\title{
Heat-Map Visualization of Gas Chromatography-Mass Spectrometry Based Quantitative Signatures on Steroid Metabolism
}

\author{
Ju-Yeon Moon, ${ }^{\mathrm{a}, \mathrm{b}}$ Hyun-Jin Jung, ${ }^{\mathrm{a}, \mathrm{b}}$ Myeong Hee Moon, \\ Bong Chul Chung, ${ }^{a}$ and Man Ho Choi ${ }^{a}$ \\ ${ }^{a}$ Life Sciences Division, Korea Institute of Science and Technology, Seoul, Korea \\ ${ }^{\mathrm{b}}$ Department of Chemistry, Yonsei University, Seoul, Korea
}

\begin{abstract}
Abnormalities in steroid hormones are responsible for the development and prevention of endocrine diseases. Due to their biochemical roles in endocrine system, the quantitative evaluation of steroid hormones is needed to elucidate altered expression of steroids. Gas chromatographic-mass spectrometric (GC-MS) profiling of 70 urinary steroids, containing 22 androgens, 18 estrogens, 15 corticoids, 13 progestins, and 2 sterols, were validated and its quantitative data were visualized using hierarchically clustered heat maps to allow "steroid signatures". The devised method provided a good linearity $\left(r^{2}>0.994\right)$ with the exception of cholesterol $\left(r^{2}=0.983\right)$. Precisions ( $\% \mathrm{CV}$ ) and accuracies (\% bias) ranged from $0.9 \%$ to $11.2 \%$ and from $92 \%$ to $119 \%$, respectively, for most steroids tested. To evaluate metabolic changes, this method was applied to urine samples obtained from 59 patients with benign prostatic hyperplasia $(\mathrm{BPH})$ versus 41 healthy male subjects. Altered concentrations of urinary steroids found and heat maps produced during this 70-compound study showed also differences between the ratios of steroid precursors and their metabolites (representing enzyme activity). Heat maps showed that oxidoreductases clustered ( $5 \alpha$-reductase, 3 $\alpha$-HSD, 3 $\beta$-HSD, and $17 \beta$-HSD, except for $20 \alpha-H S D)$. These results support that data transformation is valid, since $5 \alpha$-reductase is a marker of BPH and $17 \beta$-HSD is positively expressed in prostate cells. Multitargeted profiling analysis of steroids generated quantitative results that help to explain correlations between enzyme activities. The data transformation and visualization described may to be found in the integration with the mining biomarkers of hormone-dependent diseases. (J Am Soc Mass Spectrom 2009, 20, 1626-1637) (C 2009 American Society for Mass Spectrometry
\end{abstract}

$\mathrm{M}$ ass spectrometry based metabolite profiling reveals the metabolic states of biological systems and provides comprehensive insights by allowing comparisons between many metabolites simultaneously present in cells, tissues, or organisms [1, 2]. This technique promotes the establishment of relationships between phenotypes and metabolisms by providing descriptions of the distributions of metabolites and their biological functions. In fact, quantitative analyses of sets of metabolites in biochemical pathways have been used for physiological monitoring, toxicological evaluations, and clinical diagnosis [3-6].

Many naturally occurring steroids with similar chemical structures could yield biological information [7]. Endogenous steroids are divided into five groups, namely, androgens, estrogens, corticoids, progestins, and sterols, which are generally synthesized from cholesterol in the adrenal cortex, ovaries, and testes (Scheme 1). In biosynthetic pathways of steroid hor-

Address reprint requests to Dr. M. H. Choi, Life Sciences Division, Korea Institute of Science and Technology, 39-1 Hawolkok-dong, Seongbuk-ku, Seoul 136-791, Korea. E-mail: mh_choi@kist.re.kr mone, two major types of enzymes are involved, cytochrome P450 and steroid oxidoreductase. Abnormalities of these enzymes often lead to hormonal imbalances that have serious consequences, and which are responsible for the development of hormone-dependent diseases (see Supplementary Table 1, which can be found in the electronic version of this article). For example, concentrations of corticoids and their metabolic ratios provide diagnostic evidence of apparent mineralocorticoid excesses caused by $11 \beta$-HSD deficiency [8] and congenital adrenal hyperplasia, which are caused by deficiencies of enzymes like hydroxylase (at C-11, 17, and 21) or $3 \beta$-HSD [9]. In addition, enhanced androgen activity generated by the conversion of testosterone to dihydrotestosterone (DHT) by $5 \alpha$-reductase was utilized to allow early therapeutic intervention in young men [10].

Enzyme activity profiles can be used to describe the functional diversities of biological systems, which are driven by genetic diversity. Although enzyme activities have been monitored by following reactions between targeted enzymes and substrate molecules, overestimations by radioimmunoassay (RIA) and enzyme immunoassay (EIA), because of cross reacting antibod- 


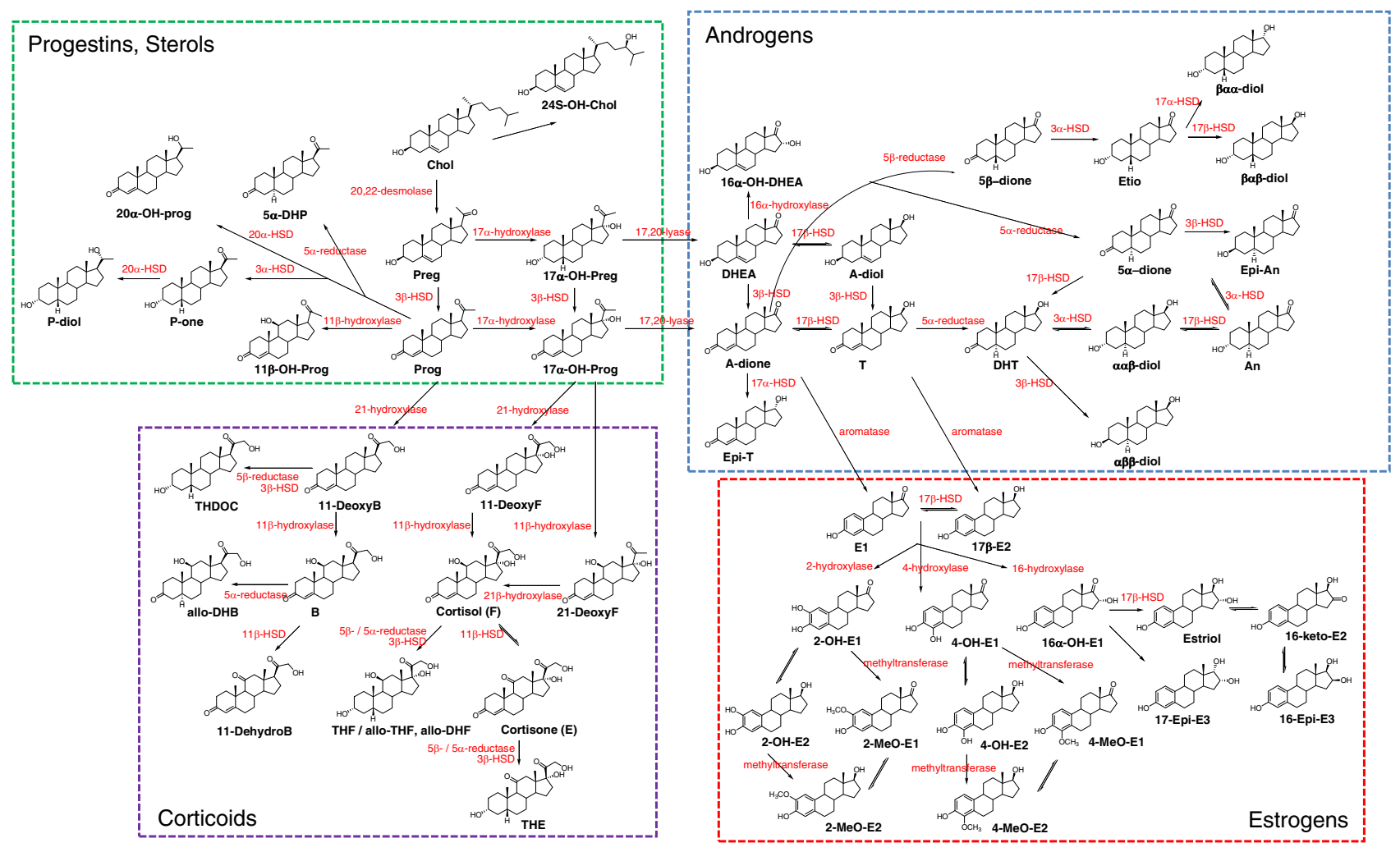

Scheme 1. General scheme for steroid metabolism in man. See Supplementary Table 1 for the full names of steroid hormones.

ies, limit the applicability of these assays, and furthermore, only single enzymes can be estimated at a time [11-14]. In contrast to conventional enzyme assays, gas chromatography-mass spectrometry (GC-MS)-based techniques have better quantitative reproducibility [15, 16]. For these reasons, GC-MS profiling has been widely used for steroid analysis [17-20], and offers the basis for techniques that can be applied to large-scale clinical studies [21].

Clinical significances are generally expressed in tables or bar graphs that show changes in analytes across groups of interest. For studies involving few compounds, these visualizations are enough to differentiate classes showing metabolic differences. However, quantitative datasets of multiple compounds are much more difficult to represent visually. Statistical clustering offers one such approach, and has been utilized to support genomic and proteomic studies [22-24]. In a similar fashion, quantitative results obtained by metabolite profiling can be directly compared between samples and utilized as metabolic biomarkers. In recent, MSbased quantitative data generated by hierarchical clustering analysis (HCA) has been subjected to pattern analysis for metabolite profiling $[2,25]$. The concept of "metabolite signature" is a result of this process, and such signatures are useful for measuring and visualizing the relative analyte concentrations. Although many groups have used GC-MS based steroid analysis for mining biomarkers, technical improvements that more effectively allow the visualization of steroid metabolites are required [26]. However, no studies have reported MS-based steroid signatures generated by HCA to date.

Here, we introduce the GC-MS quantitative profiling of 70 urinary steroids, including 22 androgens, 18 estrogens, 15 corticoids, 13 progestins, and 2 sterols, generated by HCA to evaluate metabolic changes and enzyme reactions in steroid analysis. The aim of this study was to validate a GC-MS profiling method and a method that allows the quantitative visualization of multiple urinary steroids. To visualize quantitative results, a microarray map (a type of heat map) was designed to present the urine sample results of 59 patients with benign prostatic hyperplasia (BPH) and 41 healthy male subjects; BPH was chosen because steroid metabolism is known to play a role in the progress of prostate diseases [27-29]. This study focused on illustrating the usefulness of steroid signatures for explaining both the concentrations of individual steroids and the activities of enzymes correlated global steroidogenesis in $\mathrm{BPH}$, and suggest that enzyme activity profiling may be a useful diagnostic tool and provide a means of identifying mining biomarkers in hormone-dependent diseases. 


\section{Experimental}

\section{Chemicals and Materials}

Reference standards of the 70 steroids examined in this study (Table 1) were obtained from Sigma (St. Louis, MO, USA), Steraloids (Newport, RI, USA), or NARL (Pumble, Australia). The internal standards used were, $16,16,17-d_{3}-$ testosterone and methyltestosterone for 22 androgens, $2,4,16,16-d_{4}$-estradiol for 18 estrogens, $9,11,12,12-d_{4}$-cortisol for 15 corticoids, $2,2,4,6,6,17 \alpha, 21,21,21-d_{9}$-progesterone and $2,2,4,6,6,21,21,21-d_{8}-17 \alpha$-hydroxyprogesterone for 13 progestins, and $2,2,3,4,4,6-d_{6}$-cholesterol for 2 sterols were purchased from NARL and $\mathrm{C} / \mathrm{D} / \mathrm{N}$ isotopes (PointeClaire, Quebec, Canada). For solid-phase extraction (SPE), Oasis HLB cartridge (3 mL, $60 \mathrm{mg}$; Waters, Milford, MA, USA) was preconditioned with $3 \mathrm{~mL}$ of methanol followed by $3 \mathrm{~mL}$ of deionized water. Sodium acetate (reagent grade), acetic acid (glacial, 99.99+\%) and L-ascorbic acid (reagent grade) were obtained from Sigma (St. Louis, $\mathrm{MO}$, USA). A solution of $\beta$-glucuronidase/arylsulfatase from Helix pomatia was purchased from Roche Diagnostics $\mathrm{GmbH}$ (Mannheim, Germany). The trimethylsilylating (TMS) agents, $N$-methyl- $N$-trifluorotrimethylsilyl acetamide (MSTFA), ammonium iodide $\left(\mathrm{NH}_{4} \mathrm{I}\right)$, and dithioerythritol (DTE) were purchased from Sigma. All organic solvents used were of analytical or HPLC grade and were purchased from Burdick and Jackson (Muskegan, MI, USA). Deionized water was prepared using the Milli-Q purification system (Millipore, Billerica, MA, USA).

\section{Standard Solutions and Quality-Control Samples}

Stock solutions of all reference standards were prepared at a concentration of $1000 \mu \mathrm{g} / \mathrm{mL}$ in methanol and working solutions were made up with methanol at concentrations in the range 0.1 to $10 \mu \mathrm{g} / \mathrm{mL}$. L-Ascorbic acid $(1 \mathrm{mg} / \mathrm{mL})$ was added to prevent the oxidations of labile steroid metabolites. All standard solutions were stored at $-20{ }^{\circ} \mathrm{C}$ until required and all were stable for a minimum of 3 mo. The urine samples used for calibration and quality-control (QC) purposes were prepared in house from steroid-free urine [30]. Steroids-free urine samples were prepared by percolating urine samples through Serdolit PAD-1 (0.1-0.2 mm analytical grade; Serva, Heidelberg, Germany). In this way, urinary steroids and other potential interfering compounds are retained in the cartridges and the eluates were collected. After checking for endogenous steroids with negative result following the solvent extraction procedure, they were used as matrix for steroid profiling.

\section{Subjects and Sample Collection}

First-morning urine samples were collected from 59 $\mathrm{BPH}$ patients (age: $65.3 \pm 8.2 \mathrm{y}$ male) and 41 healthy male subjects (age: $56.7 \pm 7.1 \mathrm{y}$ ) in the Department of Urology at Severance Hospital (Seoul, Korea). All patients underwent a transrectal ultrasound-guided oc- tant biopsy and had either a suspicious finding by digitorectal examination or an elevated level of serum prostate-specific antigen (PSA). The age-matched normal controls showed no evidence of serum PSA level elevation or of BPH. Steroid levels in urine were normalized versus urinary creatinine values using Jaffe method [31].

\section{Sample Preparation}

Quantitative metabolite profiling of urinary steroids was based on previous reports [4, 8, 32]. Briefly, urine samples $(2 \mathrm{~mL})$ spiked with $20 \mu \mathrm{L}$ of the 7 internal standards ( $d_{3}$-testosterone and $d_{4}$-estradiol; $1 \mu \mathrm{g} / \mathrm{mL}$, $d_{4}$-cortisol and $d_{8}-17 \alpha$-hydroxyprogesterone; $5 \mu \mathrm{g} / \mathrm{mL}$, methyltestosterone, $d_{9}$-progesterone, and $d_{6}$-cholesterol to $10 \mu \mathrm{g} / \mathrm{mL}$ ) were extracted with Oasis HLB SPE cartridges coupled to a peristaltic pump. After loading a sample onto a cartridge, the cartridge was washed with $2 \mathrm{~mL}$ water and eluted twice with $2 \mathrm{~mL}$ of methanol. Combined methanol eluates were evaporated under a stream of nitrogen and then $1 \mathrm{~mL}$ of $0.2 \mathrm{M}$ acetate buffer (pH 5.2), $100 \mu \mathrm{L}$ of aqueous $0.2 \%$ ascorbic acid, and $50 \mu \mathrm{L}$ of $\beta$-glucuronidase/arylsulfatase were was added. After incubation at $55^{\circ} \mathrm{C}$ for $3 \mathrm{~h}$, the solution was extracted twice with $2.5 \mathrm{~mL}$ of ethyl acetate: $n$-hexane (2:3, vol/vol). Combined organic solvents were evaporated using a $\mathrm{N}_{2}$ evaporator at $40{ }^{\circ} \mathrm{C}$ and further dried in a vacuum desiccator over $\mathrm{P}_{2} \mathrm{O}_{5^{-}}$ $\mathrm{KOH}$ for at least $30 \mathrm{~min}$. Finally, the dried residue was derivatized with MSTFA/ $\mathrm{NH}_{4} \mathrm{I} / \mathrm{DTE}$ (40 $\mu \mathrm{L}$; 500:4:2, $\mathrm{vol} / \mathrm{wt} / \mathrm{wt}$ ) at $60^{\circ} \mathrm{C}$ for $20 \mathrm{~min}$, and $2 \mu \mathrm{L}$ of the resulting mixture was subjected to GC-MS in selectedion monitoring (SIM) mode. To maximize extraction efficiencies, two organic solvents, tetrahydrofuran (THF) and ethyl acetate, were evaluated in the $\mathrm{pH}$ range 5 to 9 . In addition, the potential uses of diethyl ether, methyl tert-butyl ether, and $n$-hexane were investigated for promoting the partition of water-miscible THF and ethyl acetate.

\section{Instrumental Conditions}

GC-MS was performed with an Agilent 6890 Plus gas chromatograph interfaced with a single-quadrupole Agilent 5975 MSD at an electron energy of $70 \mathrm{eV}$ and an ion source temperature of $230^{\circ} \mathrm{C}$. Each sample $(2 \mu \mathrm{L})$ was injected in split mode (10:1) at $280^{\circ} \mathrm{C}$ and separated through an Ultra-1 capillary column $(25 \mathrm{~m} \times 0.2 \mathrm{~mm}$ i.d., $0.33 \mu \mathrm{m}$ film thickness; Agilent Technologies; Palo Alto, CA, USA). The GC oven temperature was initially set at $215^{\circ} \mathrm{C}$, then ramped to $260^{\circ} \mathrm{C}$ at $1^{\circ} \mathrm{C} / \mathrm{min}$, and finally increased to $320^{\circ} \mathrm{C}$ at $15^{\circ} \mathrm{C} / \mathrm{min}$ and held for 1 min. The carrier gas was helium at a column head pressure of $210.3 \mathrm{kPa}$ (column flow: $1.0 \mathrm{~mL} / \mathrm{min}$ at oven temperature of $215^{\circ} \mathrm{C}$ ). For quantitative analysis, characteristic ions of each steroid were determined as their TMS derivatives. Peak identifications were achieved by 


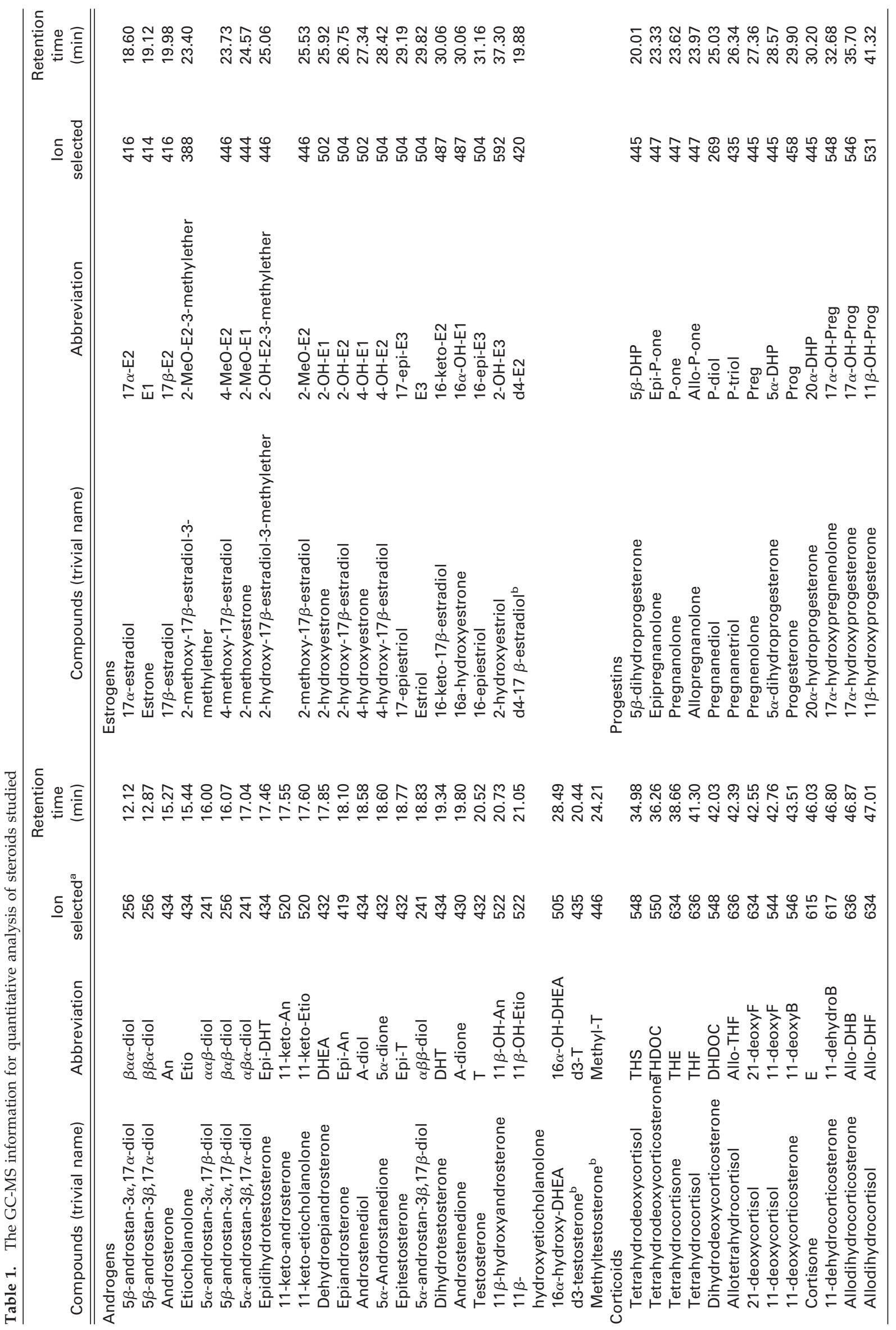




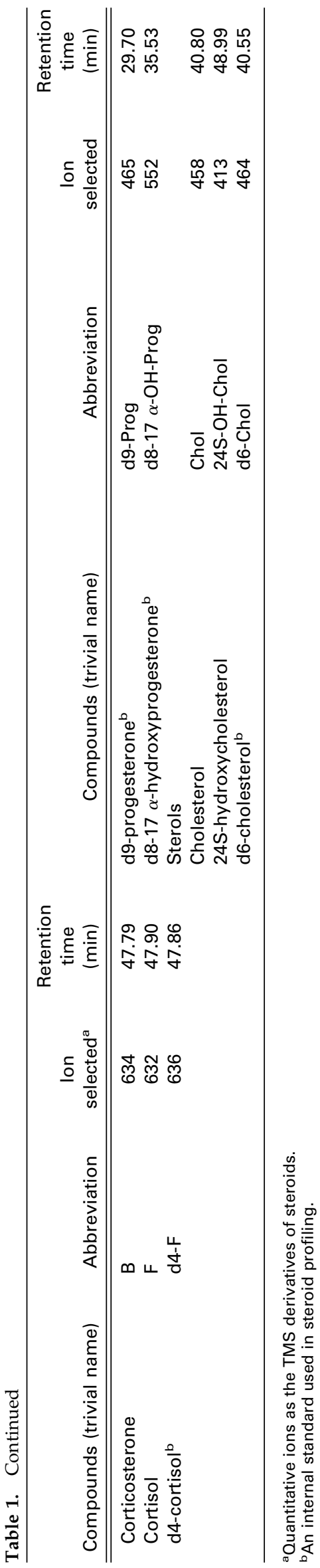

comparing retention times and matching the height ratios of characteristic ions (Table 1).

\section{Method Validation}

QC samples containing all 70 analytes were quantified using MS peak height ratios versus the IS. Calibration samples were made up at 15 different concentrations, which depended on the sensitivity and reference values of the urinary steroids. Least-squares regression analysis was performed on peak height ratios at increasing analyte levels to obtain calibration linearity. Limits of detection (LOD) and quantification (LOQ) were defined as the lowest concentration with a signal-to-noise $(\mathrm{S} / \mathrm{N})$ ratio $>3$ for $\mathrm{LOD}$ and of $\mathrm{S} / \mathrm{N}$ ratio $>10$ for LOQ. Precisions are expressed as coefficients of variation (\% $\mathrm{CV}$ ) and accuracies as percent relative errors (\% bias), and were determined using QC samples at three different concentrations (low; $2 \sim 50 \mathrm{ng} / \mathrm{mL}$, medium; $20 \sim$ $200 \mathrm{ng} / \mathrm{mL}$, and high; $100 \sim 2000 \mathrm{ng} / \mathrm{mL}$ ) depending on the sensitivity and reference values of the urinary steroids. To determine within-day repeatabilities, four replicates were analyzed, whereas day-to-day reproducibility was measured by running samples on 5 different days.

Extraction recoveries were determined using QC samples at three concentration levels in triplicate for each steroid by adding known amounts of mixed working solutions to steroid-free urine samples. Absolute recoveries were calculated by comparing peak height ratios of extracted samples versus those of their nonextracted counterparts, using the IS added just before the derivatization step.

\section{Statistical Analysis and Steroid Signatures}

Data manipulation was performed using Excel 2007 spreadsheets (Microsoft Corp., Seattle, WA, USA), Sigmaplot (SYSTAT Software Inc., San Jose, CA, USA), and SIMCA software (Umetrics Inc., Umeå, Sweden). Quantitative results are expressed as means $\pm \mathrm{SD}$, and group comparisons are made using the unpaired two-tailed Student's $t$-test. Statistical significance was considered at $P<0.01$.

To visualize differences between the steroid signatures of $\mathrm{BPH}$ patients and healthy subjects, a supervised hierarchical clustering algorithm based on Pearson's correlation coefficient was used with a TIBCO Spotfire DecisionSite Browser (TIBCO Spotfire, Inc., Somerville, MA, USA). Concentrations of steroids and ratios of metabolites to precursors (an indicator of enzyme activity) in BPH patients and healthy subjects were compared using the Student's $t$-test, and statistically significant variables were selected and processed. For clustering analysis, all prefiltered quantitative results of steroids measured and their ratios were log transformed and normalized using z-scores by subtracting population means from individual raw scores and dividing the result by the population standard deviation. 
Z-score transformation $[z=$ (observed value - baseline median)/baseline standard variation] ensures that each analyte in the subject population has a median value of 0 and a standard deviation of 1 . In the heat map generated using HCA, color coding in maps indicating auto range by difference of concentration in each compound was gradated at three point; red indicates $\mathrm{z}$ scores $>0$, blue z-scores $<0$, and white $\mathrm{z}$-scores $\approx 0$ of a row (subjects) across all columns (urinary steroids).

\section{Results and Discussion}

\section{Urinary Steroid Profiling}

Steroid hormones of significance under different biological conditions fall into several distinct groups, and are frequently used to evaluate endocrine functions. Comprehensive extraction methods for GC-MS based steroid analysis mainly focus on specific steroid metabolites which have the same biological function and chemical structures [15-17, 19]. Due to the chemical and physical diversities within androgens, estrogens, corticoids, progestins, and sterols, the described profiling technique was devised to simultaneously quantify steroid analytes as diverse as lipophilic cholesterol and hydrophilic corticoids in a single extract.

In SPE experiment, urinary steroids are purified using a unique copolymer sorbent, Oasis HLB, which allows high and reproducible results to be obtained [8, $30,32,33]$. In general, SPE absorbent retains steroids based on hydrophobic interactions with free and conjugated steroids. The following two extractions methods were therefore investigated: (1) $2 \mathrm{~mL}$ of urine was processed with a SPE cartridge and the sample obtained was hydrolyzed, and (2) urine was first hydrolyzed and then processed in SPE. However, difficulties in loading samples into SPE cartridges after hydrolyzing them with $\beta$-glucuronidase/arylsulfatases, due to an increase in the viscosity of urinary solution hydrolyzed, were observed. This result was not observed if $\beta$-glucuronidase only was present in the enzyme solution [6]. Therefore, SPE procedure was processed first in sample preparation steps.

Although catechol estrogens, such as 2-OH-E1, 2-OH$\mathrm{E} 2$, 4-OH-E1, 4-OH-E2, and 2-OH-E3, are degraded when exposed to light or to a $\mathrm{pH}$ higher than 9.5 [34], $0.2 \%$ aqueous L-ascorbic acid was added to prevent oxidative decomposition before enzymatic hydrolysis. After enzymatic hydrolysis, deconjugated steroids were extracted with an ethyl acetate: $n$-hexane (2:3, vol/vol) mix. In extraction, THF and ethyl acetate were primarily investigated, and diethyl ether, $t$-butyl methyl ether, and $n$ hexane were added to expedite THF and ethyl acetate partitioning. When relatively polar organic solvents, such as diethyl ether and t-butyl methyl ether, were used, chromatographic interference was encountered. Although both THF and ethyl acetate had high extraction efficiencies, ethyl acetate was finally selected because of the objectionable smell and high polarity of THF.
Overall extraction efficiencies were not significantly different for all steroids studied at $\mathrm{pH}$ values of 5 to 7 . The recoveries of catechol estrogens $(10.4 \%$ $\sim 48.9 \%$ ) were poor at $\mathrm{pH} 9$ because they are oxidized to quinones at this $\mathrm{pH}$ [35]. In addition, different ratios of ethyl acetate to $n$-hexane were examined and a 2:3 (vol/vol) mix was chosen having considered extraction yield and chromatographic properties. Using optimized conditions, all urinary steroids studied were extracted in good yields, except 2-OH-E3 and 24S-OH-Chol, which are still detectable in urine after extraction (Figure 1).

\section{Gas Chromatography-Mass Spectrometry}

Using the described GC-SIM/MS conditions, 70 steroid hormones were analyzed as their TMS derivatives and peak identification was straightforward using retention times, characteristic ions, chromatograms, and mass spectra, the latter were compared with those of reference standards. The GC oven program used resulted in well separated, good peak shapes for most steroids with retention times from $12.12 \mathrm{~min}$ for $\beta \alpha \alpha$-diol to $48.99 \mathrm{~min}$ for 24S-OH-Chol. On the other hand, 11-keto-An and 11-keto-Etio, and 16-keto-E2 and $16 \alpha-\mathrm{OH}-\mathrm{E} 1$ were coeluted and estimated totally in quantification (Figure 2). However, some partial-overlapped compounds (e.g., $5 \alpha$-dione and $17 \alpha$-E2, 2-OH-E2-3-methylether and Pdiol, 4-OH-E1 and Preg) were differentiated by SIM using their different characteristic ions (Table 1).

Most steroids were monitored using their molecular ions as base peaks, except: $\beta \alpha \alpha$-diol, $\beta \beta \alpha$-diol, $\beta \alpha \beta$-diol, which had an abundant [M-180; M-2OTMS ${ }^{+}$ion at $m / z$ 256; $\alpha \alpha \beta$-diol, $\alpha \beta \alpha$-diol, $\alpha \beta \beta$-diol with an [M-195; M-2OTMS- $\left.\mathrm{CH}_{3}\right]^{+}$ion at $m / z 241 ; 5 \beta$-DHP, $5 \alpha$-DHP, Preg with an $\left[\mathrm{M}-15 ; \mathrm{M}-\mathrm{CH}_{3}\right]^{+}$ion at $m / z$ 445; Epi-P-one, P-one, and Allo-P-one with an [M-15] ${ }^{+}$at $\mathrm{m} / \mathrm{z} 447$; 16-keto-E2, $16 \alpha-\mathrm{OH}-\mathrm{E} 1$ with an $[\mathrm{M}-15]^{+}$ion at $\mathrm{m} / \mathrm{z} 487$; THS with an [M-90; M-OTMS $]^{+}$ion at $m / z 548$; THE and Allo-DHF with an [M-90] $]^{+}$ion at $m / z$ 634; THF and Allo-THF with an [M-90] ${ }^{+}$ion at $m / z$ 636; 11-deoxyF with an $[\mathrm{M}-90]^{+}$ion at $\mathrm{m} / \mathrm{z} 544$; cortisone (E) with an [M-90-15; M-OTMS- $\left.\mathrm{CH}_{3}\right]^{+}$ion at $\mathrm{m} / \mathrm{z}$ 615; and 11dehydroB with an $[\mathrm{M}-15]^{+}$at $\mathrm{m} / \mathrm{z}$ 617. In the cases of P-diol, P-triol, and $11 \beta$-OH-Prog, less intense fragments at $m / z 269,435$ and 531, respectively, were chosen to improve selectivity rather than most intense peaks $(\mathrm{m} / \mathrm{z}$ 117,255 , and 546); this was attributed to urinary interference. Regarding the TMS ethers of P-diol and P-triol, the characteristic ions at $m / z 269$ and 435 were monitored, which are attributed to [M-195; M-2OTMS- $\left.\mathrm{CH}_{3}\right]^{+}$ and $\left[\mathrm{M}-117 ; \mathrm{M}-\mathrm{CH}\left[\mathrm{OSi}\left(\mathrm{CH}_{3}\right)_{3}\right] \mathrm{CH}_{3} \text { side-chain }\right]^{+}$ions. The base peak of P-diol is $\mathrm{m} / z 117$ and other important fragments are $m / z 269$ [M-90-90-15] ${ }^{+}, m / z 284$ [M-9090] ${ }^{+}, m / z 347[\mathrm{M}-117]^{+}$, and $m / z 449[\mathrm{M}-15]^{+}$. Among these fragments, $m / z 269$ instead of $m / z 117$ was chosen to improve selectivity from urinary backgrounds. Also the P-triol has $m / z 255$ [M-117-90-90] ${ }^{+}, m / z 345$ [M-117$90]^{+}$, and $m / z 435[\mathrm{M}-117]^{+}$as major fragments formed 


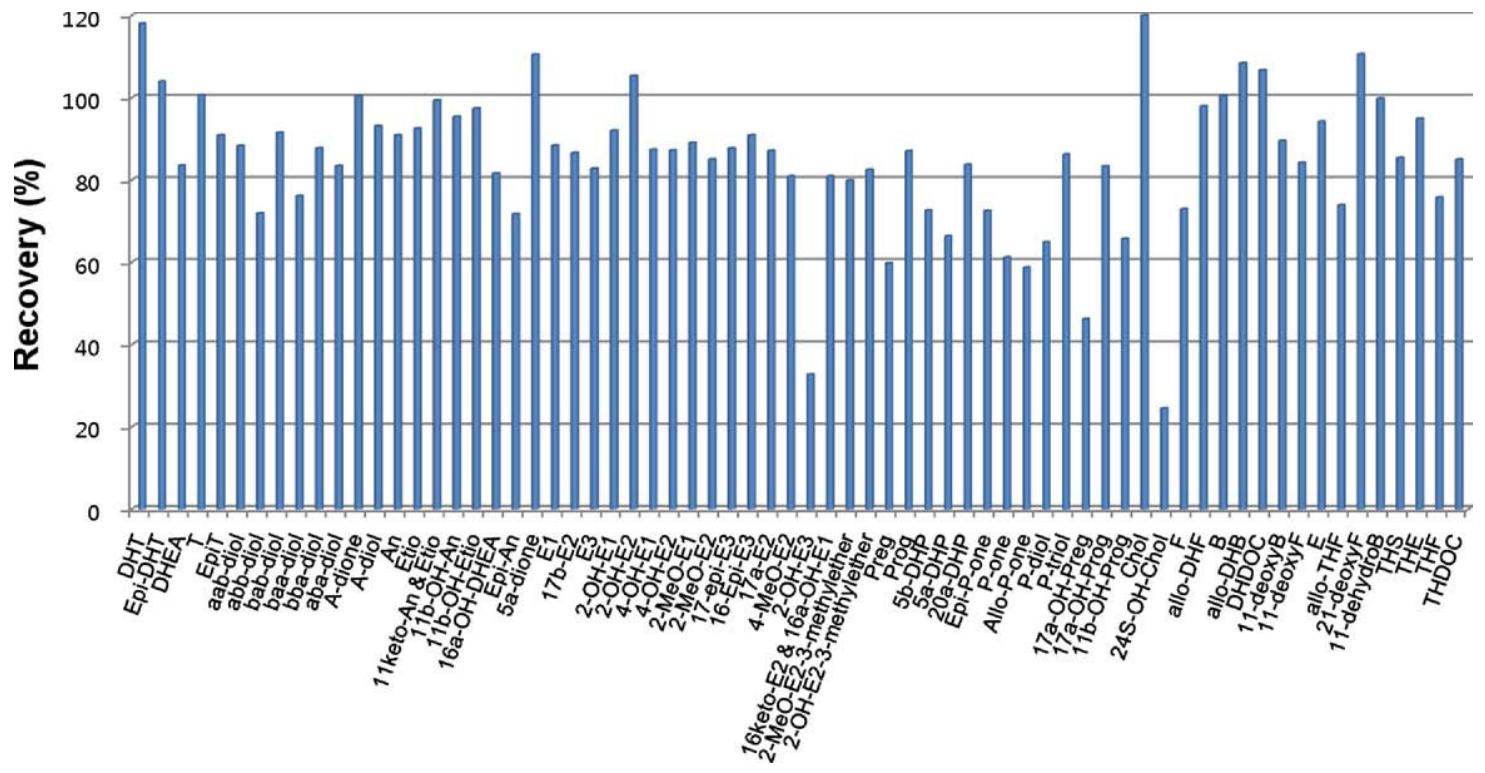

Figure 1. Extraction recoveries of 70 urinary steroids analyzed using the described method. Absolute recoveries were calculated by comparing peak height ratios of extracted samples versus their non-extracted counterparts.

by the loss of 117 mass units, but $m / z 435$ was monitored to improve selectivity. In addition, $11 \beta-\mathrm{OH}-$ Prog elutes THF at the similar retention time $(41.30 \mathrm{~min})$, but a typical loss of $90 \mathrm{Da}$ (-OTMS) from the THF $(\mathrm{m} / \mathrm{z} 636)$ would interfere the detection of $11 \beta-\mathrm{OH}-\mathrm{Prog}$ in case of using $\mathrm{m} / \mathrm{z} 546$, the molecular ion. Therefore, $\mathrm{m} / \mathrm{z} 531$ $[\mathrm{M}-90-15]^{+}$, which rarely did not exist in THF, was chosen instead of $m / z 546$ (see Supplementary Figure 1).

\section{Method Validation}

Method validation requires the evaluations of linearity, LOD, LOQ, precision, and accuracy using calibration samples prepared from in-house steroid-free urine [30]. Calibration curves were generated for all analytes using QC samples fortified with all reference standards at different concentrations. The devised method was found to be linear (correlation coefficient, $r^{2}>0.994$ ) for all analytes, except for cholesterol $\left(r^{2}=0.983\right)$. Most compounds had an LOQ in the $0.05 \sim 2.0 \mathrm{ng} / \mathrm{mL}$ range, while those of DHEA, Epi-An, $5 \alpha$-dione, $\alpha \beta \beta$-diol, 11-dehydroB, $17 \alpha-\mathrm{OH}-\mathrm{Preg}$, and $11 \beta$-OH-Prog ranged between 5.0 and $50 \mathrm{ng} / \mathrm{mL}$ (Table 2).

Assay precisions and accuracies were determined by analyzing three QC samples at different concentrations of the individual steroids $(5,20,100,200,500$, and 2000 $\mathrm{ng} / \mathrm{mL})$. Intra-day $(n=4)$ precisions (expressed as $\%$ $\mathrm{CV}$ ) ranged from $0.9 \%$ to $11.2 \%$, whereas accuracies (expressed as \% bias) ranged from 95.8 to $119.1 \%$, and inter-day $(n=5)$ precisions $(\% \mathrm{CV})$ and accuracies $(\%$ bias) ranged from $1.6 \%$ to $10.5 \%$ and from $91.6 \%$ to $115.5 \%$, respectively (Table 2). Especially, the accuracy

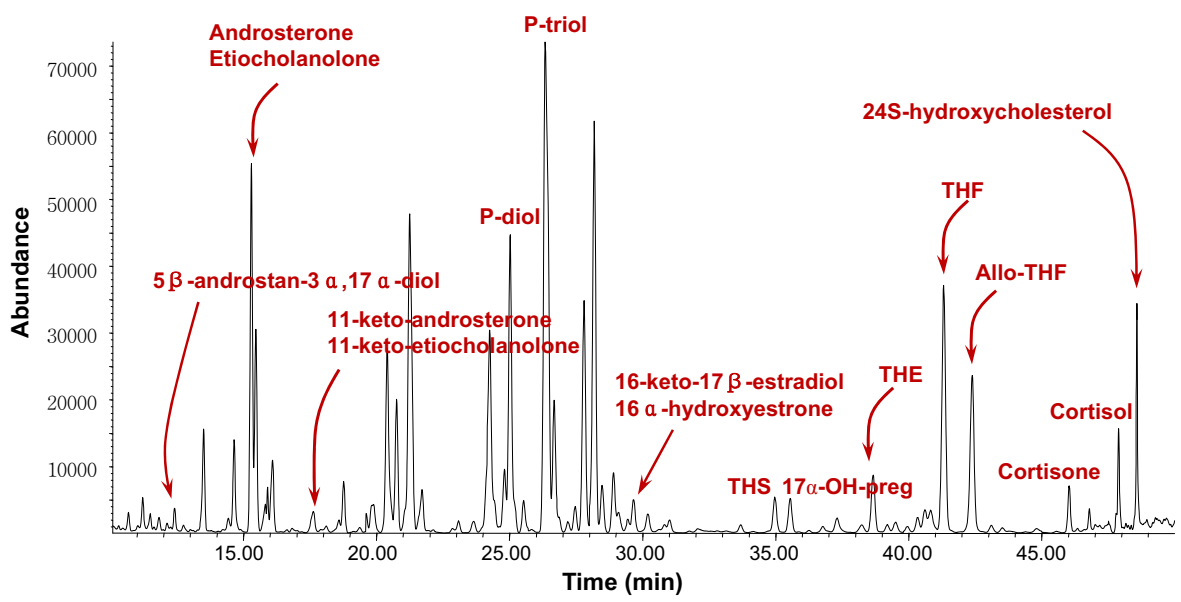

Figure 2. A representative total ion chromatogram obtained from a healthy male subject for detection of 70 urinary steroids. 
Table 2. The validation results of overall method with intra- and inter-day assays

\begin{tabular}{|c|c|c|c|c|c|c|c|c|}
\hline \multirow[b]{2}{*}{ Compounds (trivial name) } & \multirow[b]{2}{*}{$\begin{array}{c}\operatorname{LOD}^{a} \\
\text { (ng/mL) }\end{array}$} & \multirow[b]{2}{*}{$\begin{array}{c}\mathrm{LOQ}^{\mathrm{b}} \\
\text { (ng/mL) }\end{array}$} & \multirow[b]{2}{*}{$\begin{array}{c}\text { Calibration } \\
\text { range (ng/mL) }\end{array}$} & \multirow[b]{2}{*}{$\begin{array}{c}\text { Linearity } \\
\left(r^{2}\right)\end{array}$} & \multicolumn{2}{|c|}{ intra-day $(n=4)$} & \multicolumn{2}{|c|}{ inter-day $(n=5)$} \\
\hline & & & & & $\begin{array}{l}\mathrm{CV}^{\mathrm{c}} \\
(\%)\end{array}$ & $\begin{array}{c}\text { Accuracy } \\
(\%)\end{array}$ & $\begin{array}{l}\text { CV } \\
(\%)\end{array}$ & $\begin{array}{c}\text { Accuracy } \\
(\%)\end{array}$ \\
\hline \multicolumn{9}{|l|}{ Androgens } \\
\hline$\beta \alpha \alpha$-diol & 0.5 & 1.0 & $1-200$ & 0.998 & 5.9 & 104.0 & 3.8 & 97.9 \\
\hline$\beta \beta \alpha$-diol & 0.2 & 0.5 & $0.5-200$ & 0.998 & 5.7 & 107.8 & 3.1 & 105.0 \\
\hline An & 0.1 & 0.5 & $0.5-3000$ & 0.996 & 3.2 & 119.1 & 3.5 & 108.8 \\
\hline Etio & 0.1 & 0.5 & $0.5-3000$ & 0.998 & 2.5 & 106.1 & 2.2 & 109.7 \\
\hline$\alpha \alpha \beta$-diol & 0.5 & 1.0 & $1-200$ & 0.998 & 6.8 & 111.4 & 3.3 & 109.6 \\
\hline$\beta \alpha \beta$-diol & 0.2 & 0.5 & $0.5-200$ & 0.998 & 4.4 & 106.2 & 3.0 & 109.1 \\
\hline$\alpha \beta \alpha$-diol & 1.0 & 2.0 & $2-200$ & 0.995 & 5.2 & 107.5 & 3.4 & 103.4 \\
\hline Epi-DHT & 0.1 & 0.2 & $0.2-200$ & 0.994 & 8.0 & 106.0 & 3.4 & 108.9 \\
\hline 11-keto-An \& Etio & 0.1 & 0.5 & $0.5-1000$ & 0.996 & 3.7 & 108.4 & 3.4 & 112.3 \\
\hline DHEA & 5.0 & 50.0 & $50-3000$ & 0.997 & 3.5 & 106.6 & 3.3 & 108.2 \\
\hline Epi-An & 2.0 & 5.0 & $5-1000$ & 0.994 & 2.5 & 98.0 & 2.1 & 109.5 \\
\hline A-diol & 0.5 & 2.0 & $2-200$ & 0.996 & 7.4 & 116.3 & 10.5 & 97.2 \\
\hline $5 \alpha$-dione & 0.5 & 5.0 & $10-200$ & 0.995 & 4.8 & 106.2 & 2.2 & 111.8 \\
\hline Epi-T & 0.05 & 0.1 & $0.1-200$ & 0.997 & 3.8 & 100.7 & 1.6 & 100.8 \\
\hline$\alpha \beta \beta$-diol & 10.0 & 20.0 & $20-500$ & 0.998 & 6.9 & 104.0 & 3.0 & 104.0 \\
\hline DHT & 0.1 & 0.2 & $0.2-200$ & 0.998 & 4.7 & 109.6 & 2.4 & 102.7 \\
\hline A-dione & 0.05 & 0.1 & $0.1-200$ & 0.999 & 5.7 & 103.4 & 2.4 & 101.7 \\
\hline $\mathrm{T}$ & 0.05 & 0.1 & $0.1-200$ & 0.998 & 4.7 & 106.1 & 1.9 & 102.5 \\
\hline $11 \beta-\mathrm{OH}-\mathrm{An}$ & 0.2 & 0.5 & $0.5-3000$ & 0.997 & 3.4 & 104.6 & 5.8 & 112.9 \\
\hline $11 \beta-\mathrm{OH}$-Etio & 0.2 & 0.5 & $0.5-3000$ & 0.998 & 2.7 & 101.3 & 4.1 & 113.4 \\
\hline $16 \alpha-\mathrm{OH}-\mathrm{DHEA}$ & 0.1 & 0.2 & $0.2-1000$ & 0.996 & 4.0 & 104.3 & 1.7 & 105.8 \\
\hline \multicolumn{9}{|l|}{ Estrogens } \\
\hline $17 \alpha-\mathrm{E} 2$ & 0.05 & 0.1 & $0.1-200$ & 0.998 & 3.9 & 98.6 & 2.6 & 96.3 \\
\hline E1 & 0.1 & 0.2 & $0.2-200$ & 0.998 & 2.9 & 99.0 & 2.0 & 97.3 \\
\hline $17 \beta-\mathrm{E} 2$ & 0.05 & 0.1 & $0.1-200$ & 0.997 & 3.5 & 99.8 & 2.3 & 97.2 \\
\hline 2-MeO-E2-3-methylether & 0.1 & 0.2 & $0.2-200$ & 0.998 & 2.9 & 97.3 & 2.1 & 96.4 \\
\hline 4-MeO-E2 & 0.2 & 0.5 & $0.5-200$ & 0.998 & 2.1 & 98.7 & 1.8 & 95.6 \\
\hline 2-MeO-E1 & 0.05 & 0.1 & $0.1-200$ & 0.998 & 1.9 & 99.0 & 1.8 & 95.8 \\
\hline 2-OH-E2-3-methylether & 0.1 & 0.2 & $0.2-200$ & 0.998 & 4.2 & 101.3 & 2.4 & 97.6 \\
\hline 2-MeO-E2 & 0.05 & 0.1 & $0.1-200$ & 0.998 & 4.3 & 100.2 & 2.2 & 97.1 \\
\hline 2-OH-E1 & 0.1 & 0.2 & $0.2-200$ & 0.998 & 4.9 & 104.7 & 3.7 & 99.5 \\
\hline 2-OH-E2 & 0.1 & 0.2 & $0.2-200$ & 0.998 & 6.1 & 106.4 & 3.4 & 99.3 \\
\hline 4-OH-E1 & 0.1 & 0.2 & $0.2-200$ & 0.998 & 2.9 & 103.2 & 2.5 & 98.8 \\
\hline 4-OH-E2 & 0.1 & 0.2 & $0.2-200$ & 0.998 & 4.6 & 100.1 & 4.2 & 97.3 \\
\hline 17-epi-E3 & 0.5 & 1.0 & $1-200$ & 0.997 & 2.4 & 106.7 & 2.4 & 100.3 \\
\hline E3 & 0.2 & 0.5 & $0.5-200$ & 0.997 & 2.7 & 101.6 & 2.8 & 99.7 \\
\hline 16-keto-E2 and $16 \alpha-\mathrm{OH}-\mathrm{E} 1$ & 0.1 & 0.2 & $0.2-500$ & 0.998 & 2.7 & 98.7 & 8.8 & 92.5 \\
\hline 16-epi-E3 & 0.5 & 1.0 & $1-200$ & 0.997 & 3.5 & 103.2 & 2.3 & 100.5 \\
\hline 2-OH-E3 & 0.5 & 1.0 & $1-100$ & 0.997 & 5.0 & 107.4 & 5.3 & 101.0 \\
\hline \multicolumn{9}{|l|}{ Corticoids } \\
\hline THS & 0.1 & 0.2 & $0.2-200$ & 0.997 & 0.9 & 99.2 & 3.0 & 98.4 \\
\hline THDOC & 0.2 & 0.5 & $0.5-200$ & 0.996 & 7.1 & 100.4 & 4.1 & 100.0 \\
\hline THE & 1.0 & 2.0 & $2-500$ & 0.997 & 7.6 & 151.4 & 9.9 & 151.3 \\
\hline THF & 0.2 & 0.5 & $0.5-200$ & 0.998 & 6.6 & 106.1 & 4.9 & 104.0 \\
\hline DHDOC & 0.5 & 1.0 & $1-200$ & 0.997 & 4.2 & 101.2 & 4.1 & 104.9 \\
\hline Allo-THF & 0.2 & 0.5 & $0.5-500$ & 0.996 & 4.8 & 103.9 & 2.6 & 102.6 \\
\hline 21-deoxyF & 0.5 & 1.0 & $1-200$ & 0.997 & 7.3 & 108.5 & 4.8 & 109.3 \\
\hline 11-deoxyF & 0.2 & 0.5 & $0.5-200$ & 0.998 & 2.9 & 98.5 & 3.5 & 91.6 \\
\hline 11-deoxyB & 0.5 & 1.0 & $1-200$ & 0.997 & 6.9 & 100.3 & 2.9 & 105.1 \\
\hline Cortisone (E) & 0.2 & 0.5 & $0.5-500$ & 0.998 & 3.2 & 101.2 & 2.7 & 99.8 \\
\hline 11-dehydroB & 0.2 & 5.0 & $5-200$ & 0.994 & 2.1 & 101.8 & 2.7 & 100.4 \\
\hline Allo-DHB & 0.5 & 1.0 & $1-200$ & 0.997 & 6.9 & 113.1 & 5.3 & 108.0 \\
\hline Allo-DHF & 1.0 & 2.0 & $2-200$ & 0.997 & 2.3 & 97.5 & 2.9 & 107.3 \\
\hline Corticosterone (B) & 0.2 & 0.5 & $0.5-200$ & 0.997 & 3.3 & 99.0 & 3.3 & 100.3 \\
\hline Cortisol (F) & 0.1 & 0.2 & $0.2-200$ & 0.998 & 3.0 & 100.5 & 3.5 & 98.0 \\
\hline \multicolumn{9}{|l|}{ Progestins } \\
\hline $5 \beta$-DHP & 0.1 & 0.2 & $0.2-100$ & 0.997 & 9.9 & 109.2 & 3.5 & 110.5 \\
\hline Epi-P-one & 1.0 & 2.0 & $2-200$ & 0.995 & 4.1 & 106.0 & 3.0 & 105.8 \\
\hline P-one & 1.0 & 2.0 & $2-200$ & 0.997 & 7.4 & 110.1 & 3.3 & 115.5 \\
\hline Allo-P-one & 0.2 & 0.5 & $0.5-200$ & 0.994 & 2.9 & 109.9 & 2.2 & 103.7 \\
\hline
\end{tabular}


Table 2. Continued

\begin{tabular}{|c|c|c|c|c|c|c|c|c|}
\hline \multirow[b]{2}{*}{ Compounds (trivial name) } & \multirow[b]{2}{*}{$\begin{array}{c}\mathrm{LOD}^{\mathrm{a}} \\
(\mathrm{ng} / \mathrm{mL})\end{array}$} & \multirow[b]{2}{*}{$\begin{array}{c}\mathrm{LOQ}^{\mathrm{b}} \\
(\mathrm{ng} / \mathrm{mL})\end{array}$} & \multirow[b]{2}{*}{$\begin{array}{l}\text { Calibration } \\
\text { range }(\mathrm{ng} / \mathrm{mL})\end{array}$} & \multirow[b]{2}{*}{$\begin{array}{l}\text { Linearity } \\
\left(r^{2}\right)\end{array}$} & \multicolumn{2}{|c|}{ intra-day $(n=4)$} & \multicolumn{2}{|c|}{ inter-day $(n=5)$} \\
\hline & & & & & $\begin{array}{l}\mathrm{CV}^{\mathrm{c}} \\
(\%)\end{array}$ & $\begin{array}{l}\text { Accuracy } \\
\text { c (\%) }\end{array}$ & $\begin{array}{l}\mathrm{CV} \\
(\%)\end{array}$ & $\begin{array}{c}\text { Accuracy } \\
(\%)\end{array}$ \\
\hline P-diol & 0.5 & 1.0 & $1-500$ & 0.997 & 6.2 & 105.6 & 3.6 & 107.5 \\
\hline P-triol & 0.2 & 0.5 & $0.5-500$ & 0.999 & 6.0 & 102.8 & 2.3 & 105.5 \\
\hline Preg & 1.0 & 2.0 & $20-200$ & 0.995 & 8.8 & 104.1 & 3.5 & 98.5 \\
\hline $5 \alpha-\mathrm{DHP}$ & 0.2 & 0.5 & $0.5-200$ & 0.995 & 7.0 & 99.2 & 3.8 & 104.0 \\
\hline Prog & 0.5 & 1.0 & $1-100$ & 0.998 & 4.8 & 96.0 & 2.5 & 98.6 \\
\hline $20 \alpha-\mathrm{DHP}$ & 0.2 & 0.5 & $0.5-100$ & 0.997 & 9.1 & 101.7 & 4.9 & 103.8 \\
\hline $17 \alpha$-OH-Preg & 5.0 & 10.0 & $20-500$ & 0.998 & 3.6 & 98.7 & 3.0 & 102.9 \\
\hline $17 \alpha$-OH-Prog & 0.2 & 0.5 & $0.5-200$ & 0.996 & 3.1 & 95.8 & 2.3 & 96.1 \\
\hline $11 \beta-\mathrm{OH}-$ Prog & 2.0 & 5.0 & $5-500$ & 0.996 & 11.2 & 103.9 & 7.3 & 94.3 \\
\hline \multicolumn{9}{|l|}{ Sterols } \\
\hline Chol & 1.0 & 2.0 & $50-1000$ & 0.983 & 7.3 & 113.0 & 7.8 & 115.0 \\
\hline 24S-OH-Chol & 0.5 & 2.0 & $2-200$ & 0.994 & 6.5 & 96.3 & 4.1 & 100.9 \\
\hline
\end{tabular}

The limit of detection was measured $\mathrm{S} / \mathrm{N}$ ratio $>3$

b The limit of quantification was measured $S / N$ ratio $>10$

'Precision and accuracy were expressed as the mean values of data obtained from three different concentrations for each analyte.

of THE resulted in abnormal values, and it might be produced by low calibration slope because of poor GC-MS properties.

\section{Quantitative Results of Benign Prostatic Hyperplasia}

The validated quantitative profiling method was applied to measure 70 endogenous steroids in urine samples obtained from $59 \mathrm{BPH}$ patients and 41 agematched healthy male subjects. All quantitative results, corrected by urinary creatinine levels, were compared, and differences between patients and healthy subjects were evaluated using the Student's t-test. Although it was not the purpose of this study to elucidate clinical implications, some features were notable, and significant differences were found between patients and healthy subjects (see Supplementary Figure 2).

In patients, urinary levels of $\mathrm{T}, \mathrm{Epi}-\mathrm{T}, \alpha \alpha \beta$-diol, $\beta \alpha \beta$-diol, $\beta \beta \alpha$-diol, 17 $\beta$-E2, 11 $\beta$-OH-Prog, and $16 \alpha-\mathrm{OH}-$ DHEA were significantly decreased $\left(P=4.52 \times 10^{-4} \sim\right.$ $\left.2.77 \times 10^{-13}\right)$, and those of $11 \beta-\mathrm{OH}$-Etio, $\alpha \beta \beta$-diol, 2-OH-E3, $17 \alpha$-OH-Prog, and 11-deoxyF were significantly increased $\left(P=4.56 \times 10^{-7} \sim 9.42 \times 10^{-18}\right)$. Some other urinary steroids quantified were also significantly different in patients and controls $(P<0.01)$. Changes in the urinary levels of $\alpha \alpha \beta$-diol and $\alpha \beta \beta$-diol were in accord with previous findings $[36,37]$, but other steroid changes observed in this study have not been reported to date. In particular, urinary $17 \beta-\mathrm{E} 2$ and $2-\mathrm{OH}-\mathrm{E} 3$ showed remarkable changes with $P$ values of $2.77 \times$ $10^{-13}$ and $4.25 \times 10^{-9}$, which might be associated with the different biochemical roles of estrogen receptor $\alpha$ $(\mathrm{ER} \alpha)$ and $\beta(\mathrm{ER} \beta)$ in various types of prostate cells [28, 38, 39]. The involvements of other urinary steroids needs to future study.

\section{Steroid Signatures by Hierarchical Clustering Analysis}

The present MS-based steroid profiling has become an essential clinical tool and has produced many results in $\mathrm{BPH}$, but it is difficult to identify critical differences between patients and controls because of the large number of results. Hierarchical clustering, which involves calculating the distance matrices of data objects and then merging objects that are close to each other to form sub-clusters, has been utilized in biomedical studies to interpret the expressions of biomolecules [2, 22-25]. In the present study, after determining the relative levels of each steroid, all data were z-score transformed to produce a heat map using a supervised HCA based on Pearson's correlation coefficient. The raw data were the relative concentrations of the 70 urinary steroids, and these were filtered by statistical significance $(P<0.01)$ using the Student's $t$-test. The clustering method and similarity measure were set unweighted average and Euclidean distance, respectively. Urinary concentrations were represented by colors in the heat map, and each steroid was represented by a single row of colored boxes, whereas columns represented different subjects. Heat maps were compared with respect to individual quantitative results, and indicated the effectiveness of steroid signatures.

Figure 3 illustrates in a heat map showing altered concentrations of urinary steroids in $\mathrm{BPH}$ patients and healthy subjects. The heat map readily shows changes in the concentrations of urinary steroids. Increased urinary excretion patterns of several steroids, from Epi-DHT down to 11-deoxyF, were detected in patients, while other steroid levels were significantly reduced. In addition, visual inspections of steroid signatures complemented quantitative statistics. Although 2-OH-E3 was present at a significantly higher level in patients $\left(P=4.25 \times 10^{-9}\right.$; see Supplementary Figure 2), these increases were only ob- 


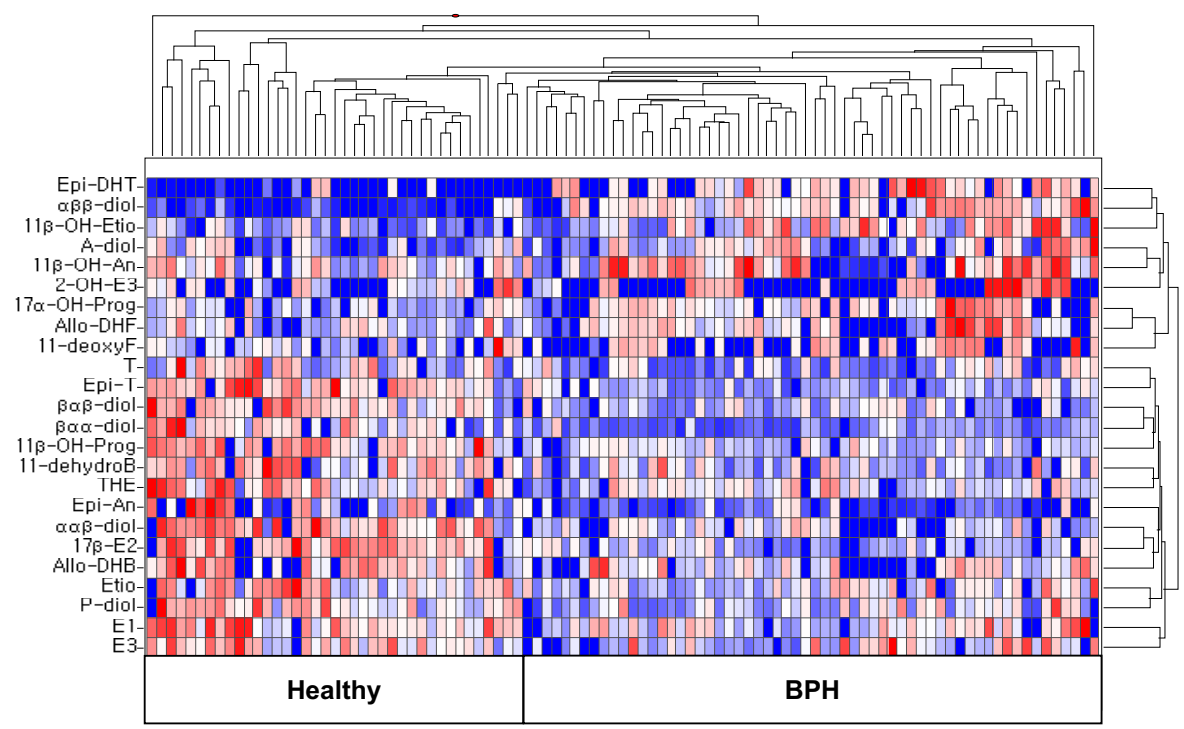

Figure 3. Hierarchically clustered heat map of the urinary steroids levels of $59 \mathrm{BPH}$ patients and 41 healthy male subjects. Differences between steroid levels in controls and patients were examined using Student's $t$-test, and only those that were significantly different at the $P<0.01$ level were selected. Row represents subjects and column urinary concentration of individual steroids. Cells are colored based on concentrations in urinary samples. Red represents highly excreted into urine and blue showed a concentration in urine.

served in some patients in the heat map. The levels of other steroids, 11 $\beta$-OH-Etio and 11-deoxyF, were also inconsistency different in patients (Figure 3).

To illustrate further the usefulness of a steroid signature, the ratio of steroid metabolite to precursor, which reflects enzyme activity (Scheme 1), was examined. The cluster and heat maps of all analyzed samples in this 70 compound study showed differences between groups in these ratios (Figure 4). A dendrogram of ratios revealed that the oxidoreductases formed a cluster ( $5 \alpha$-reductase, $3 \alpha$-HSD, $3 \beta$-HSD, and $17 \beta$-HSD, except for $20 \alpha$-HSD; see Supplementary Table 1 for full enzyme names), which are differentiated with a cytochrome P450 enzyme, $11 \beta$-hydroxylase. These results support the validity of the data transformation, since $5 \alpha$-reductase is a marker of
$\mathrm{BPH}$ [27-29], and $17 \beta-\mathrm{HSD}$ is positively expressed in prostate cells $[40,41]$. Other up-regulated enzymes in the map might be biomarkers of BPH. Furthermore, the method can be used to visualize quantitative steroid data in a single graphic using a hierarchically clustered heat map. The need for this type of visualization arises from the complexity of large experimental datasets. One important advantage of using a heat map is that it can be used to visualize clinical data across multiple subjects for many analytes, which allows patterns to be easily identified.

\section{Conclusions}

Due to the clinical requirement to quantify trace levels of urinary endogenous steroids, we devised an analyt-

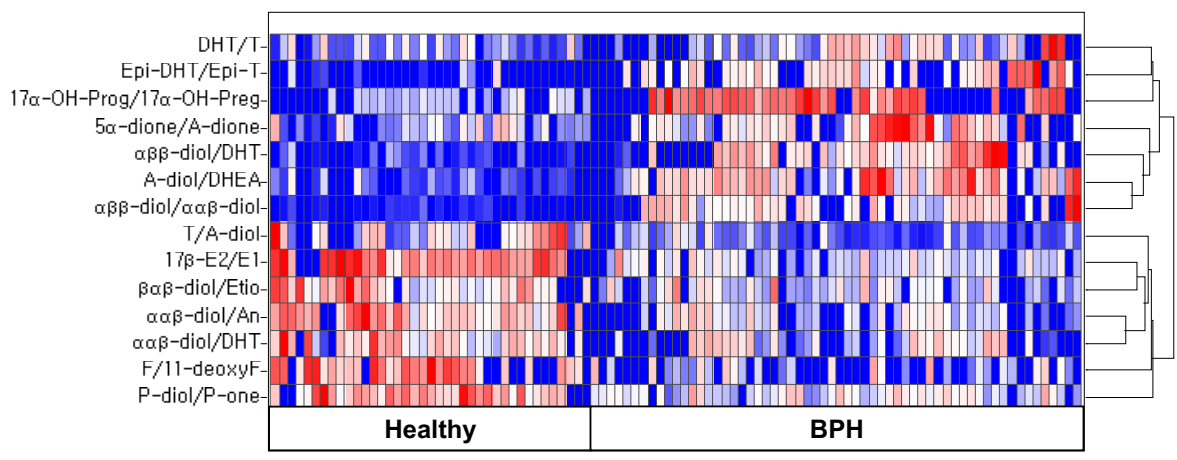

Figure 4. A heat map for measuring enzyme activities related to steroid metabolism. The ratio of precursor to metabolite for each steroid was calculated, and only steroids with level differences significant at the $P<0.01$ level were selected. Rows represent subjects and column metabolic ratio. Red represents a high ratio and blue a low ratio. 
ical method to measure the individual concentrations of 70 urinary steroids and several enzyme activities based on steroid signatures using a single assay, which substantially reduces analytical time and sample size. In contrast to classical biochemical approaches using RIA and EIA that mainly focus on single enzymes, single metabolic reactions, and kinetic properties, profiling analysis involves the collation of quantitative results for a broad series of metabolites to gain an overall understanding of metabolism.

Steroid signatures as represented by hierarchically clustered heat maps use color to communicate underlying quantitative results, which are much harder to appreciate when presented numerically. This method is simple to implement and maintains the biological integrity of data. Using this technique, inter-relationships between absolute concentrations and enzyme activities in samples from different sources can be recognized. The combined GC-MS profiling technique described has adequate sensitivity that could be used for high throughput analysis, and could be adopted to enable the quantifications of urinary steroids and indicate metabolic alterations at biologically relevant levels.

\section{Acknowledgments}

The authors acknowledge support for this work by an intramural grant from the Korean Institute of Science and Technology (KIST), and by grants from the National $\mathrm{R}$ and $\mathrm{D}$ Program of the Korean Ministry of Education, Science, and Technology (MEST), and the Korean Science and Engineering Foundation (KOSEF).

\section{Appendix A Supplementary Material}

Supplementary material associated with this article may be found in the online version at doi:10.1016/ j.jasms.2009.04.020.

\section{References}

1. Nicholson, J.; Lindon, J.; Holmes, E. 'Metabonomics': Understanding the metabolic responses of living systems to pathophysiological stimuli via multivariate statistical analysis of biological NMR spectroscopic data. Xenobiotica 1999, 29, 1181-1189.

2. Kaddurah-Daouk, R.; Kristal, B. S.; Weinshilboum, R. M. Metabolomics: a global biochemical approach to drug response and disease. Annu. Rev. Pharmacol. Toxicol. 2008, 48, 653-683.

3. Dalle-Donne, I.; Rossi, R.; Colombo, R.; Giustarini, D.; Milzani, A. Biomarkers of oxidative damage in human disease. Clin. Chem. 2006, 52, 601-623.

4. Lee, S. H.; Woo, H. M.; Jung, B. H.; Lee, J. A.; Kwon O. S.; Pyo, H. S.; Choi, M. H.; Chung, B. C. Metabolomic approach to evaluate the toxicological effects of nonylphenol with rat urine. Anal. Chem. 2007, 79, 6102-6110.

5. Falk, R. T.; Xu, X.; Keefer, L.; Veenstra, T. D.; Ziegler, R. G. A liquid chromatography-mass spectrometry method for the simultaneous measurement of 15 urinary estrogens and estrogen metabolites: assay reproducibility and interindividual variability. Cancer Epidemiol. Biomarkers Prev. 2008, 17, 3411-3418.

6. Cho, H.-J.; Kim, J. D.; Lee, W.-Y.; Chung, B. C.; Choi, M. H. Quantitative metabolic profiling of 21 endogenous corticosteroids in urine by liquid chromatography-triple quadrupole-mass spectrometry. Anal. Chim. Acta 2009, 632, 101-108.

7. Falkenstein, E.; Tillmann, H. C.; Christ, M.; Feuring, M.; Wehling, M. Multiple actions of steroid hormones-a focus on rapid, nongenomic effects. Pharmacol. Rev. 2000, 52, 513-555.
8. Choi, M. H.; Hahm, J. R.; Jung, B. H.; Chung, B. C. Measurement of corticoids in the patients with clinical features indicative of mineralocorticoid excess. Clin. Chim. Acta 2002, 320, 95-99.

9. Caulfield, M. P.; Lynn, T.; Gottschalk, M. E.; Jones, K. L.; Taylor, N. F.; Malunowicz, E. M.; Shackleton, C. H. L.; Reitz, R. E.; Fisher, D. A. The diagnosis of congenital adrenal hyperplasia in the newborn by gas chromatography/mass spectrometry analysis of random urine specimens. J. Clin. Endocrinol. Metabol. 2002, 87, 3682-3690.

10. Choi, M. H.; Yoo, Y. S.; Chung, B. C. Biochemical roles of testosterone and epitestosterone to $5 \alpha$-reductase as indicators of male-pattern baldness. J. Invest. Dermatol. 2001, 116, 57-61.

11. Wong, T.; Shackleton, C. H.; Covey, T. R.; Ellis, G. Identification of the steroids in neonatal plasma that interfere with $17 \alpha$-hydroxyprogesterone radioimmunoassays. Clin. Chem. 1992, 38, 1830-1837.

12. Minutti, C. Z.; Lacey, J. M.; Magera, M. J.; Hahn, S. H.; McCann, M.; Schulze, A.; Cheillan, D.; Dorche, C.; Chace, D. H.; Lymp, J. F.; Zimmerman, D.; Rinaldo, P.; Matern, D. Steroid profiling by tandem mass spectrometry improves the positive predictive value of newborn screening for congenital adrenal hyperplasia. J. Clin. Endocrinol. Metabol. 2004, 89, 3687-3693.

13. Nelson, R. E.; Grebe, S. K.; O'Kane, D. J.; Singh, R. J. Liquid chromatographytandem mass spectrometry assay for simultaneous measurement of estradiol and estrone in human plasma. Clin. Chem. 2004, 50, 373-384.

14. Santen, R. J.; Demers, L.; Ohorodnik, S.; Settlage, J.; Langecker, P. Blanchett, D.; Goss, P. E.; Wang, S. Superiority of gas chromatography/ tandem mass spectrometry assay (GC/MS/MS) for estradiol for monitoring of aromatase inhibitor therapy. Steroids 2007, 72, 666-671.

15. Hsing, A. W.; Stanczyk, F. Z.; Bélanger, A.; Schroeder, P.; Chang, L.; Falk, R. T.; Feras, T. R. Reproducibility of serum sex steroid assays in men by RIA and mass spectrometry. Cancer Epidemiol. Biomarkers. Prev. 2007, 16, 1004-1008.

16. Wood, L.; Ducroq, D. H.; Fraser, H. L.; Gillingwater, S.; Evans, C. Pickett, A. J.; Rees, D. W.; John, R.; Turkes, A. Measurement of urinary free cortisol by tandem mass spectrometry and comparison with results obtained by gas chromatography-mass spectrometry and two commercial immunoassays. Ann. Clin. Biochem. 2008, 45, 380-388.

17. Palermo, M.; Gomez-Sanchez, C.; Roitman, E.; Shackleton, C. H. L. Quantitation of cortisol and related 3-oxo-4-ene steroids in urine using gas chromatography/mass spectrometry with stable isotope-labeled internal standards. Steroids 1996, 61, 583-589.

18. Homma, K.; Hasegawa, T.; Masumoto, M.; Takeshita, E.; Watanabe, K.; Chiba, H.; Kurosawa, T.; Takahashi, T.; Matsuo, N. Reference values for urinary steroids in Japanese newborn infants: gas chromatography/ mass spectrometry in selected ion monitoring. Endocrinol. J. 2003, 50, 783-792.

19. Meffre, D.; Pianos, A.; Liere, P.; Eychenne, B.; Cambourg, A.; Schumacher, M.; Stein, D. G.; Guennoun, R. Steroid profiling in brain and plasma of male and pseudopregnant female rats after traumatic brain injury: analysis by gas chromatography/mass spectrometry. Endocrinology 2007, 148, 2505-2517.

20. Moon, J.-Y; Jung, H.-J.; Moon, M. H.; Chung, B. C.; Choi, M. H. Inclusion complex-based solid-phase extraction of steroidal compounds with entrapped beta-cyclodextrin polymer. Steroids 2008, 73, 1090-1097.

21. Semmes, O. J. Defining the role of mass spectrometry in cancer diagnostics. Cancer Epidemiol. Biomarkers Prev. 2004, 13, 1555-1557.

22. Rhodes, D. R.; Chinnaiyan, A. M. Integrative analysis of the cancer transcriptome. Nat. Genet. 2005, 37, S31-S37.

23. Ivshina, A. V.; Geroge, J.; Senko, O.; Mow, B.; Putti, T. C.; Smeds, J.; Lindahl, T.; Pawitan, Y.; Hall, P.; Nordgren, H.; Wong, J. E. L.; Liu, E. T.; Bergh, J.; Kuznetxov, V. A.; Miller, L. D. Genetic reclassification of histologic grade delineates new clinical subtypes of breast cancer. Cancer Res. 2006, 66, 10292-10301.

24. Ray, S.; Britschgi, M.; Herbert, C.; Takeda-Uchimura, Y.; Boxer, A.; Blennow, K.; Friedman, L. F.; Galasko, D. R.; Jutel, M.; Karydas, A.; Kaye, J. A.; Leszek, J.; Miller, B. L.; Minthon, L.; Quinn, J. F.; Rabinovici, G. D.; Robinson, W. H.; Sabbagh, M. N.; So, Y. T.; Sparks, D. L.; Tabaton, M.; Tinklenberg, J.; Yesavaga, J. A.; Tibschirani, R.; Wyss-Coray, T. Classification and prediction of clinical Alzheimer's diagnosis based on plasma signaling proteins. Nat. Med. 2007, 13, 1359-1362.

25. Denkert, C.; Budczies, J.; Kind, T.; Weichert, W.; Tablack, P.; Sehouli, J.; Niesporek, S.; Konsgen, D.; Dietel, M.; Fiehn, O. Mass spectrometrybased metabolic profiling reveals different metabolite patterns in invasive ovarian carcinomas and ovarian borderline tumors. Cancer Res. 2006, 66, 10795-10804.

26. Dettmer, K.; Aronov, P. A.; Hammock, B. D. Mass spectrometry-based metabolomics. Mass Spectrom. Rev. 2007, 26, 51-78.

27. Choi, M. H.; Kim, J. N.; Chung, B. C. Rapid HPLC-electrospray tandem mass spectrometric assay for urinary testosterone and dihydrotestosterone glucuronides from patients with benign prostate hyperplasia. Clin. Chem. 2003, 49, 322-325.

28. McPherson, S. J.; Ellem, S. J.; Simpsn, E. R.; Patchev, V.; Fritzemeier K.-H.; Risbridger, G. P. Essential role for estrogen receptor $\beta$ in stromal-epithelial regulation of prostatic hyperplasia. Endocrinology 2007, 148, 566-574.

29. Luu-The, V: Bélanger, A. Labrie, F. Androgen biosynthetic pathways in the human prostate. Best Pract. Res. Clin. Endocrinol. Metabol. 2008, 22, 207-221.

30. Cho, Y. -D.; Choi, M. H. Alternative sample preparation techniques in gas chromatographic-mass spectrometric analysis of urinary androgenic steroids. Bull. Korean Chem. Soc. 2006, 27, 1315-1322. 
31. Husdan, H.; Rapoport, A. Estimation of creatinine by the Jaffe reaction. A comparison of three methods. Clin. Chem. 1968, 14, 222-238.

32. Choi, M. H.; Kim, K.-R.; Hong, J. K.; Park, S. J.; Chung, B. C. Determination of nonsteroidal estrogens in breast milk, plasma, urine, and hair by gas chromatography/mass spectrometry. Rapid Commun. Mass. Spectrom. 2002, 16, 2221-2228.

33. Reddy, S.; Iden, C. R.; Brownawell, B. J. Analysis of steroid conjugates in sewage influent and effluent by liquid chromatography-tandem mass spectrometry. Anal. Chem. 2005, 77, 7032-7038.

34. Xu, X.; Veenstra, T. D.; Fox, S. D.; Roman, J. M.; Issaq, H. J.; Falk, R.; Saavedra, J. E.; Keefer, L. K.; Ziegler, R. G. Measuring fifteen endogenous estrogens simultaneously in human urine by high-performance liquid chromatography-mass spectrometry. Anal. Chem. 2005, 77, 6646-6654.

35. Bolton, J. L.; Thatcher, G. R. J. Potential mechanisms of estrogen quinone carcinogenesis. Chem. Res. Toxicol. 2008, 21, 93-101.

36. Wright, F.; Poizat, R.; Bongini, M.; Bozzolan, F.; Doukani, A.; MauvaisJarvis, P. Decreased urinary $5 \alpha$-androstane- $3 \alpha, 17 \beta$-diol glucuronide excretion in patients with benign prostatic hyperplasia. J. Clin. Endocriol. Metabol. 1985, 60, 294-298.
37. Bauman, D. R.; Steckelbroeck, S.; Peehl, D. M.; Penning, T. M. Transcript profiling of the androgen signal in normal prostate, benign prostatic hyperplasia, and prostate cancer. J. Clin. Endocriol. Metabol. 2006, 147, 5806-5816.

38. Tsurusaki, T.; Aoki, D.; Kanetake, H.; Inoue, S.; Muramatsu, M. Hishikawa, Y.; Koji, T. Zone-dependent expression of estrogen receptors $\& ; \alpha$ and $\beta$ in human benign prostatic hyperplasia. J. Clin. Endocriol. Metabol. 2003, 88, 1333-1340.

39. Prins, G. S.; Korach, K. S. The role of estrogens and estrogen receptors in normal prostate growth and disease. Steroids 2008, 73, 233-244.

40. Martel, C.; Rhéaume, E.; Takahashi, M.; Trudel, C.; Couét, J.; Luu-The, V.; Simard, J.; Labrie, F. Distribution of $17 \beta$-hydroxysteroid dehydrogenase gene expression and activity in rat and human tissues. J. Steroid Biochem. Mol. Biol. 1992, 41, 597-603.

41. Délos, S.; Carsol, J. -L.; Fina, F.; Raynaud, J.-P.; Martin, P.-M. 5 $\alpha$-Reductase and $17 \beta$-hydroxysteroid dehydrogenase expression in epithelial cells from hyperplastic and malignant human prostate. Int. J. Cancer 1998, 75, 840-846. 